\title{
The Role of Positive 3-H Words in Peacebuilding and Engagement in EFL/ESL Classes
}

\author{
Xiaojing Shi* \\ Center for Second Language Writing Research/School of College English Teaching and Research, Henan University, Kaifeng, \\ China
}

This review aimed at investigating the role of help, hope, and harmony formally known as positive $3 \mathrm{H}$ on students' engagement and peacebuilding. This topic has recently attracted attention since teachers and the way they treat students are said to play a paramount role in the learning process and as a result, peace can be built in the classroom and students also are more likely to be actively engaged in the tasks. To start with, a definition for positive 3-H was presented coupled with the role it plays in language learning contexts. Then the way both inner peace and interpersonal peace have been applied in the learning process to build peace is discussed. Following that, the effects of positive 3-H on students' engagement and peacebuilding through raising some relevant activities are dealt with. Finally, implications and further directions are put forward.

\section{OPEN ACCESS}

Edited by: Ali Derakhshan, Golestan University, Iran

Reviewed by: Jieping $X u$, Chaohu University, China Liqaa Habeb Al-Obaydi, University of Diyala, Iraq

*Correspondence: Xiaojing Shi xiaojinglucy@outlook.com

Specialty section: This article was submitted to Educational Psychology, a section of the journal Frontiers in Psychology

Received: 22 July 2021 Accepted: 04 August 2021 Published: 27 August 2021

Citation:

Shi X (2021) The Role of Positive 3-H Words in Peacebuilding and Engagement in EFL/ESL Classes. Front. Psychol. 12:745645. doi: 10.3389/fpsyg.2021.745645
Keywords: positive $3 \mathrm{H}$, peacebuilding, engagement, emotions, English as a second/foreign language

\section{INTRODUCTION}

People's hearts and minds are found to be undoubtedly affected by language and words, and the effect might be either short-term or long-term (Lewandowska-Tomaszczyk et al., 2020). It has always been people's natural desire to feel connected to a community and fit in with a group of people; therefore, long-lasting relationships can be strongly dependent on the amount to which a person can communicate interpersonally (Holmes, 2008). In terms of positive $3-\mathrm{H}$ and peacebuilding, a cognitive dimension of learning is involved as well as a linguistic one. Positive $3-\mathrm{H}$ (Help, Hope, and Harmony) (Curtis and Oxford, 2021) indicates how individuals can thrive and be happier, concentrating on positive emotions like hope, enthusiasm, resilience, positivity, and so forth rather than negative feelings (Dewaele, 2015; MacIntyre et al., 2019; Li, 2020; Li et al., 2020). The process of deeper learning is affected by learners' variables such as well-being, self-efficacy, etc. Moreover, students reach the expected consequences of education as long as they are provided with a positive ambiance coupled with a rapport between teachers and students throughout the class that can be regarded as a social context since it is a microcosm of society. Having given that a language learning situation where students have to struggle with learning a new language and practices through which peace can be built seem crucially significant. These mentioned practices have been conceptualized in both positive psychology and positive peace psychology characterized by the way people thrive and the amount they can actively build peace rather than growing negative senses within themselves (Gibson, 2011; MacIntyre and Mercer, 2014). The present article aims to scrutinize three positive aspects of classroom language (i.e., help, hope, harmony) and their effects on both peacebuilding and students' engagement in the classroom context. For more clarification, some activities, through which peace can be built and negative emotions can be reduced, have been added as well. 


\section{BACKGROUND}

\section{Definitions of the Positive 3-H Words}

Education is not merely giving students information; instead, through the given information, students' lives should be harmonized. The phrase Positive 3H (Curtis and Oxford, 2021) refers to hope, help, and harmony. Regarding the pivotal role of positive emotions, many studies have proven the fact that a feeling of being engaged, being motivated, being successful, being efficacious, being interested, accomplishing one's goals, performance, and so forth, are enhanced (Derakhshan et al., 2019; MacIntyre et al., 2019; Li, 2020). To explicate it more, "Hope" has been defined in positive psychology in a cognitive theory as (a) an individual's belief in his capabilities and as a consequence of it, mental goals and desired future aims can be envisioned, paving the way to move toward one's goals and (b) the ability and motivation to start and feel determined as they are striving hard to achieve their goals. According to Snyder's model, the higher the levels of enduring hope, the greater the academic entrance exam scores and the higher the self-esteem would be. As a matter of fact, the process of learning a new language is anxiety-provoking, and it is the teachers' hopeful comments that help students not to lose hope (Snyder, 2000). In terms of "Help," the considerable role of teachers is emphasized because through their caring help and encouraging words, students' anxiety can be assuaged and weakened; accordingly, students' communicative abilities can be expressed to the people by whom they are surrounded. It can vividly be interpreted that a rapid decline in students' motivation can be halted as challenging situations along with supportive, helpful encouragement are provided by both the teachers and mentors (Curtis and Oxford, 2021). "Harmony" refers to people living and working together without fighting and disagreeing with each other. Empathy, which means the experience of people's feelings and thoughts, has been shown to be the stepping stone to human "Harmony" (Oxford, 2016). Another aspect from which harmony can be taken into consideration is change since learning a new language needs one to give up his comfort zone. Change that is extremely stressful at times can be experienced by the students who are seriously studious since change challenges the items which are familiarized to us and thus, one's normal needs for safety, being comfortable, and having control over what has been done are questioned. Despite the fact that no one likes to experience the feeling of being disturbed within themselves, it is an inseparable part of growing (Singer, 2007).

\section{The Definition and Application of Negative 3-H Words}

As for positive emotion, Curtis and Oxford (2021) raised another taxonomy in which hateful, hurtful, and harmful language is stressed. They might seem synonymous at the first glance; however, they can be used in their own contexts. "Hate" refers to a feeling of dislike. It can be shown in many communicative contexts from personal to societal. A serious argument, for example, is caused by using a hateful language. "Hurt" and "Harm" seems the same in that both bring about physical and emotional injury, yet the point is that the degree of injury would be higher when harming someone. Similarly, hurt sometimes has a positive effect, while harm does not.

One of the activities that can be put into practice is using insults in L1 so as to stop using them in L2. Care should be taken so as not to offend anyone in the class since the words are so insulting that they cannot be used in public. According to Dewaele (2011) teachers perceive that both boredom and anxiety are the most important sources for lack of improvement in foreign language learning that may be caused by being hurt in the learning context. It is hence not surprising that researchers in SLA and in language teaching research have concentrated on ways to provide a positive and stimulating learning environment in order to engage learners and enhance their language learning motivation (Dewaele, 2011).

\section{Applying Peacebuilding for Inner Peace}

When learning a new language, the students' aim is twofold: to acquire knowledge about the language and speak it fluently and to raise educational knowledge to teach foreign language learners; thus, the learning process is impacted by the emotions either positively or negatively (Swain, 2011). Students' motivations, attention, and self-regulation either favorably or unfavorably are the emotions that are affected through this process. In recent years, emotions have received a more significant role in academic studying as they have been demonstrated to affect students' persistence and the strategies applied for it, students' engagement, learning, and accomplishments. So considering positive 3 -Hs and positive psychology in which improving positive emotions, increasing engagements, appreciating meaning in life are highlighted, positive emotion makes learning easier since it has a tendency to widen one's horizon, therefore resulting in an increase in attention, creativity, and thriving (Fredrickson, 2001).

Furthermore, students' emotions can be managed and regulated so that positivity would be ameliorated. Regulating emotion can be enhanced through a conversation with people who are more capable either peers or teachers (Vygotsky, 1978). With regard to this method, a goal is activated, strategies are opted for and applied, an outcome is identified, and consequently, emotions can be regulated. Regarding that, Inner peace is linked to a person's emotions, it can be easily jeopardized by internal stressors, such as the lack of emotion regulation and self-direction, in addition to external factors (Oxford, 2017a,b). It can be taken as an example, university students put a strain on themselves to achieve specific goals and they are expected not to fail (Pekrun et al., 2002). These are the internal threats that may lead to unpleasant learning results. With regard to the above example, negative emotions cannot often be managed successfully and may put both inner peace and well-being in danger.

The two main categories of peace in L2 education are inner peace and interpersonal peace; the former is concerned with one's peace within himself, and the latter is peace with whom you know. Inner peace was defined as a state of well-being that does not depend on the presence of external or internal pleasurable stimuli. In the L2 learning context, inner peace is relevant to learners' characteristics and self-concept which is 
about the beliefs such as self-esteem, self-confidence, and selfefficacy that learners have about their abilities and how they evaluate their competence in the context of L2 learning (Williams et al., 2016). Self-concept can also be influenced by friendly teachers supporting their students so that the students can be encouraged to learn from their mistakes so both self-esteem and self-confidence can be boosted in the students in this way; hence, they develop their beliefs about themselves even faster contributing to enhancing their inner peace.

\section{The Effect of Positive 3-H on Students' Engagement and Peacebuilding}

Engagement refers to the amount learners participate actively in the activities. Engaged learners can be responsible for their learning and it is unlikely to attain meaningful learning without being engaged. Engagement is said to be context-specific, for instance, learners' culture, family, school, peers affect their engagement (Hiver et al., 2021). Learner engagement is a complex construct consisting of multiple dimensions which together contribute to successful learning. Wang and Derakhshan (2021) highlighted that affective, social, behavioral, and cognitive dimensions of engagement are interrelated, leading to the improvement of particular habits and attitudes toward learning. Most language professionals have reached the agreement that for communicative skills to be mastered, participation is the key to success and it takes learners' passionate engagement (MacIntyre and Gregersen, 2012). What can be pinpointed is that disengagement gives rise to a reduction in positive emotions, such as self-esteem and self-regulation and an increase in helplessness (Derakhshan, 2021).

Some activities have been created to involve the students and help them build peace. According to Gregersen and MacIntyre (2021), the activities should not be necessarily content-specific, but a positive psychological context should be set that could cause more meaningful learning. One of the organized activities is classified into three phases: forethought, performance, reflection. In the first phase, the task was analyzed by the students to understand and be alert about the emotions that were felt, throughout oral production. During the second phase, they were persuaded to monitor their performance and the focus was on the experienced emotions during the task; as a result, they could perceive how to regulate the emotions. Through the last phase, they were promoted to estimate how these strategies aid them in finding inner peace (Oxford, 2017b).

\section{Implications and Future Directions}

As emotions are of great importance in building one's character and helping one develop a sense of tranquility to learn a new language, this study has focused on positive emotions known as positive $3-\mathrm{H}$ words which facilitate the process of learning. Consequently, there are a few restrictions that should be kept in mind and should also be addressed in future studies. Even though emotions are said to play a paramount role in the process of learning, surprisingly it has received little attention. Had students been provided with helpful ideas, a harmonious learning situation, and hopeful comments and encouragement, peace could have been built through the process of learning and anxiety would have been lowered. Studies have been conducted to collect information about what types of emotions impede the process of learning; however, a few studies were carried out to describe a learning atmosphere in which positive $3-\mathrm{H}$ words are applied in all aspects, and building peace is the most crucial priority. Honestly, when peace is built, most of the negative feelings, impeding the learning process, will be diminished and thus, the process of learning will be facilitated. As it has been explained, both linguistic and cognitive dimensions should be taken into account if we expect one to grow faster in terms of personality and grasping a new language. So from an institutional point of view, teachers should be trained to utilize positive $3-\mathrm{H}$ words while teaching so that students feel blissfully happy and they can cope with stress which arises while learning a new language. Yet, high engagement is highly unlikely to be achieved through classes. Nonetheless, as it was proposed by Schlechty (2011), one which is not hard to achieve is that most students should be involved most of the time. In this regard, researchers should conduct both qualitative and longitudinal studies for monitoring these activities applied through the class and their long-term effects on students' educational and personal lives. Additionally, thanks to state-of-the-art technology and a fast-changing world, a new way of interacting between teachers and students has been put forward, online classes, so emphasis should be laid on how and why anxiety is experienced during such classes.

\section{AUTHOR CONTRIBUTIONS}

The author confirms being the sole contributor of this work and has approved it for publication.

\section{FUNDING}

This study was sponsored by the 10th batch of Chinese Foreign Language Education Fund Project Construction and Application of College English Wisdom Classroom Model from the Perspective of Teacher-student Community (Grant No. ZGWYJYJJ10A069).

\section{REFERENCES}

Curtis, A., and Oxford, R. L. (2021). "Exploring peace language: hope, help and harmony," in Peace Building in Language Education, eds R. Oxford, M. M. Olivero, M. Harrison, and T. Gregersen (Bristol: Multilingual Matters), 228-241.
Derakhshan, A. (2021). The predictability of Turkman students' academic engagement through Persian language teachers' nonverbal immediacy and credibility. J. Teach. Persian Speakers Other Lang. 10, 3-26. doi: 10.30479/jtpsol.2021.14654.1506

Derakhshan, A., Saeidi, M., and Beheshti, F. (2019). The interplay between Iranian EFL teachers conceptions of intelligence, 
care, feedback, and students' stroke. IUP English Stud. 14, 81-98.

Dewaele, J. M. (2011). Reflections on the emotional and psychological aspects of foreign language learning and use. Anglistik 22, 23-42.

Dewaele, J. M. (2015). On emotions in foreign language learning and use. Lang. Teach. 39, 13-15. doi: 10.37546/JALTTLT39.3-3

Fredrickson, B. L. (2001). The role of positive emotions in positive psychology: the broaden-and-build theory of positive emotions. Am. Psychol. 56, 218-226. doi: 10.1037/0003-066X.56.3.218

Gibson, S. (2011). Social psychology, war and peace: towards a critical discursive peace psychology. Soc. Pers. Psychol. Compass 5, 239-250. doi: 10.1111/j.1751-9004.2011.00348.x

Gregersen, T., and MacIntyre, P. D. (2021). "Acting locally to integrate positive psychology and peace: practical applications for language teaching and learning," in Peace-Building in Language Education, eds R. Oxford, M. M. Olivero, M. Harrison, and T. Gregersen (Bristol: Multilingual Matters), 177-195.

Hiver, P., Al-Hoorie, A. H., Vitta, J. P., and Wu, J. (2021). Engagement in language learning: a systematic review of 20 years of research methods and definitions. Lang. Teach. Res. doi: 10.1177/13621688211001289

Holmes, P. (2008). Foregrounding harmony: Chinese international students' voices in communication with their New Zealand peers. Chin. Media Res. 4, 102-110.

Lewandowska-Tomaszczyk, B., Monello, V., and Venuti, M. (2020). Language, Heart, and Mind: Studies at the Intersection of Emotion and Cognition (Łódz Studies in Language) (New ed.). Bern: Peter Lang. doi: 10.3726/b16874

Li, C. (2020). A positive psychology perspective on Chinese EFL students' trait emotional intelligence, foreign language enjoyment and EFL learning achievement. J. Multilingual Multicult. Dev. 41, 246-263. doi: 10.1080/01434632.2019.1614187

Li, C., Dou, R., and Zhang, S. (2020). A correlational study on psychological resilience and L2 demotivation among Chinese EFL learners. Revista Argentina de Clínica Psicológica 29, 670-681. doi: 10.24205/03276716.2020.770

MacIntyre, P., and Gregersen, T. (2012). Emotions that facilitate language learning: the positive-broadening power of the imagination. Stud. Second Lang. Learn. Teach. 2, 193-213. doi: 10.14746/ssllt.2012.2.2.4

MacIntyre, P. D., Gregersen, T., and Mercer, S. (2019). Setting an agenda for positive psychology in SLA: Theory, practice, and research. Modern Lang. J. 103, 262-274. doi: 10.1111/modl.12544

MacIntyre, P. D., and Mercer, S. (2014). Introducing positive psychology to SLA. Stud. Second Lang. Learn. Teach. 4, 153-172. doi: 10.14746/ssllt.20 14.4.2.2

Oxford, R.L. (2016). "Toward a psychology of well-being for language learners: the 'EMPATHICS' vision," in Positive Psychology in Second Language Acquisition, eds P. MacIntyre, T. Gregersen, and S. Mercer (Bristol: Multilingual Matters), 10-87. doi: 10.21832/97817830953 60-003
Oxford, R.L. (2017a). "Peace through understanding: Peace activities as innovations in language teacher education," in Innovative Practices in Language Teacher Education: Spanning the Spectrum From Intra- to Inter-Personal Professional Development, eds T. Gregersen, and P. MacIntyre (New York, NY: Springer), 125-164. doi: 10.1007/978-3-319-51789-6_7

Oxford, R.L. (2017b). Teaching and Researching Language Learning Strategies: Self-Regulation in Context. New York, NY: Routledge.

Pekrun, R., Goetz, T., Titz, W., and Perry, R. P. (2002). "Positive emotions in education," in Beyond Coping: Meeting Goals, Visions, and Challenges, ed E. Frydenberg (Oxford: Oxford University Press), 149-173. doi: 10.1093/med:psych/9780198508144.003.0008

Schlechty, P. C. (2011). Engaging Students: The Next Level of Working on the Work. Hoboken, NJ: John Wiley \& Sons.

Singer, M. A. (2007). The Untethered Soul: The Journey Beyond Yourself, 1st Edn. Oakland, CA: New Harbinger Publications/ Noetic Books.

Snyder, C.R. (2000). "Hypothesis: there is no hope," in Handbook of Hope: Theory, Measures, and Applications, ed C.R. Snyder (San Diego, CA: Academic Press), 3-21. doi: 10.1016/B978-012654050-5/50003-8

Swain, M. (2011). The inseparability of cognition and emotion in second language learning. Lang. Teach. 46, 195-207. doi: 10.1017/S0261444811000486

Vygotsky, L. S. (1978). Socio-cultural theory. Mind Soc. 6, 52-58.

Wang, Y. L., and Derakhshan, A. (2021). Review of the Book Investigating Dynamic Relationships Among Individual Difference Variables in Learning English as a Foreign Language in a Virtual World, by M. Kruk. System. Cham: Springer.

Williams, M., Mercer, S., and Ryan, S. (2016). Exploring Psychology in Language Learning and Teaching (Oxford Handbooks for Language Teachers) (Illustrated ed.). Oxford: Oxford University Press.

Conflict of Interest: The author declares that the research was conducted in the absence of any commercial or financial relationships that could be construed as a potential conflict of interest.

Publisher's Note: All claims expressed in this article are solely those of the authors and do not necessarily represent those of their affiliated organizations, or those of the publisher, the editors and the reviewers. Any product that may be evaluated in this article, or claim that may be made by its manufacturer, is not guaranteed or endorsed by the publisher.

Copyright (c) 2021 Shi. This is an open-access article distributed under the terms of the Creative Commons Attribution License (CC BY). The use, distribution or reproduction in other forums is permitted, provided the original author $(s)$ and the copyright owner(s) are credited and that the original publication in this journal is cited, in accordance with accepted academic practice. No use, distribution or reproduction is permitted which does not comply with these terms. 